\title{
RFLP analysis of resistance to the barley yellow mosaic virus complex
}

\author{
A Graner 1, E Bauer 1, A Kellermann 1, G Proeseler 2, G Wenzel, F Ordon ${ }^{3}$ \\ 1 Federal Centre for Breeding Research on Cultivated Plants, Institute for Resistance Genetics, D-85461 Grünbach; \\ 2 Federal Centre for Breeding Research on Cultivated Plants, Institute for Epidemiology and Resistance, D-06449 Aschersleben; \\ 3 Institute for Crop Science and Plant Breeding, Justus-Liebig-University, D-35390 Giessen, Germany
}

(Received 15 May 1995; accepted 3 July 1995)

\begin{abstract}
Summary - The barley yellow mosaic virus complex consists of barley mild mosaic virus (BaMMV), barley yellow mosaic virus type 1 (BaYMV-1) and barley yellow mosaic virus type 2 (BaYMV-2). In an attempt to investigate the genetic basis of resistance to these pathogens, a series of genes, including 3 novel previously undescribed ones, have been identified in cultivated barley (Hordeum vulgare). They vary in their specificity for individual members of this virus complex and were localized within the barley genome using a set of mapped RFLP markers. Along with previously characterized resistance genes, 9 different genes have now been described in barley. These form 2 major complexes on the long arms of chromosomes 3 and 4 consisting of 4 and 3 loci, respectively.
\end{abstract}

genetics / Hordeum vulgare = barley / BaYMV / BaMMV / disease resistance / RFLP marker

Résumé - Analyse par RFLP de la résistance au complexe des virus des mosaïques des orges. Ce complexe de la mosaïque jaune de l'orge est formé par le virus de la mosaïque modérée de l'orge (BaMMV), le virus de la mosaïque jaune de l'orge type 1 (BaYMV-1) et le virus de la mosaïque jaune de l'orge type 2 (BaYMV-2). Lors d'une étude du déterminisme génétique de la résistance à ces agents pathogènes, une série de gènes, incluant 3 nouveaux gènes non décrits précédemment, a été identifiée chez l'orge cultivée (Hordeum vulgare L). Ces gènes diffèrent pour leur spécificité envers chacun des membres du complexe de virus et ont été localisés sur le génome de l'orge à l'aide d'un ensemble de marqueurs RFLP déjà cartographiés. En incluant les gènes déjà charactérisés, 9 gènes différents ont maintenant été décrits chez l'orge. Is forment 2 complexes majeurs situés sur les bras longs des chromosomes 3 et 4 , composés respectivement de 4 et 3 loci.

génétique / Hordeum vulgare / virus de la mosaïque modérée de l'orge / virus de la mosaïque jaune de l'orge / résistance aux maladies / marqueur RFLP

\section{INTRODUCTION}

Barley yellow mosaic virus (BaYMV-1, BaYMV-2) and barley mild mosaic virus (BaMMV) represent major pathogens of winter barley in central Europe. During the fall and winter season virus particles are transmitted via the fungal vector Polymyxa graminis into root cells (Adams et al, 1988) from where they spread systemically throughout the plant. Due to the soil-borne transmission of the viruses, barley plants cannot be protected by chemical means and cultivation of

\footnotetext{
${ }^{*}$ Correspondence and reprints
} 
winter barley in infested areas depends entirely on the availability of disease-resistant cultivars.

Resistance of European winter barley cultivars to BaYMV-1 and BaMMV rests predominantly on a single recessive gene (ym4) conferring complete immunity (Friedt and Foroughi-Wehr, 1987). This gene has been located on the long arm of chromosome 3 (Graner and Bauer, 1993) and has been introgressed from the south European landrace Ragusa into more than 20 European cultivars. A few years ago, a new BaYMV strain (BaYMV-2) was discovered due to its virulence on hitherto resistant cultivars carrying the $y m 4$ gene (Huth, 1989) thus necessitating further attempts to breed resistant cultivars. As a first result the cultivar Hiberna was released showing resistance to BaYMV-1 and BaYMV-2 (Baumer, personal communication).

In contrast to the narrow genetic basis of virus resistance in cultivated barley, a survey of unadapted germplasm has revealed a series of new sources for resistance to BaMMV and BaYMV (Ordon et al, 1992). Four types of resistant germplasm can be differentiated: (1) resistance to BaMMV only; (2) resistance to both BaMMV and BaYMV-1; (3) resistance to BaYMV-1 and BaYMV-2; and (4) resistance to BaMMV, BaYMV-1 and BaYMV-2. Genetic analysis of resistant germplasm disclosed the presence of several non-allelic genes (Ordon and Friedt, 1993). Due to their mostly exotic origin most of the resistant barley lines lack winter hardiness and resistance to major fungal pathogens. Therefore, introgression of the corresponding resistance genes into adapted European winter barley requires extensive backcrossing followed by time-consuming tests for disease resistance in the greenhouse and in the field, both of which are not satisfactory on the single plant level. Moreover, because of the recessive inheritance of most resistance genes, heterozygous carriers cannot be identified on the phenotypic level. Hence, efficient breeding strategies require both a refined knowledge of the genetic basis of disease resistance and improved diagnostic procedures. In this context, the availability of several well-saturated molecular marker maps for the barley genome (Graner et al, 1991; Heun et al, 1991; Kleinhofs et al, 1993) provides the basis for (1) the chromosomal localization of resistance genes; and (2) the identification of closely linked, selectable markers. This report describes the genetic localization by RFLP markers of a series of new genes, which will form the basis for broadening the genetic base of resistance to BaYMV and BaMMV in cultivated winter barley.

\section{MATERIALS AND METHODS}

\section{RFLP and linkage analysis}

DNA extraction, digestion and hybridization were performed as described previously (Graner et al, 1991). Linkage analysis was conducted using Mapmaker computer software (Lander et al, 1987).

\section{Resistance tests}

Mechanical inoculation of BaMMV was performed according to Friedt (1984). Field tests were carried out at 2 locations one of which (Tölzkirchen, Bavaria) was infested with BaYMV-1 only and the other (Schladen, Lower Saxonia) with both BaYMV-1 and BaYMV2. Virus infection was tested by ELISA using antibodies specific for either BaYMV or BaMMV, which were kindly provided by Dr W Huth (Federal Biological Research Centre for Agriculture and Forestry, Braunschweig).

\section{RESULTS}

Resistance genes were localized by linkage analysis using a set of mapped RFLP markers. Linkage analysis in the progenies described below was performed in a 2-step procedure. In a preliminary screening, RFLP markers linked to the respective resistance genes were identified by analyzing bulks of 10 resistant and 10 susceptible progeny plants each. Linked markers were subsequently mapped by RFLP analysis of the complete population. Linkage data of the genes described below are summarized in table I.

\section{ym7}

Genetic analysis of this gene was performed in a population consisting of $69 \mathrm{~F}_{1}$ derived doubled haploid barley lines from a cross between $\mathrm{H}$ Hor 3365 (resistant to BaMMV) and the cv Borwina. As expected for a monogenic trait, the progeny segregated in a $1: 1$ ratio into resistant and susceptible lines. The corresponding gene $(y m 7)$ maps on the short arm of barley chromosome 5 close to the centromere, where it is tagged by several closely linked RFLP markers. It should be noted, however, that presence of the $y m 7$ genes does not confer complete immunity. Resistant plants are characterized by a delay in symptom development and virus propagation. 
Table I. Compilation of RFLP mapping data on resistance to BaYMV and BaMMV.

\begin{tabular}{|c|c|c|c|c|c|}
\hline Gene & Source & Specificity & Chromosome & Marker a & Distance (CM) \\
\hline$y m 5$ & $W 122 / 37.1 \mathrm{~b}$ & BaMMV, BaYMV-1, BaYMV-2 & $3 L$ & MWG10 & 1.1 \\
\hline$y m 5^{\prime}$ & Iwate Omugi1 & BaMMV, BaYMV-1 c & $3 L$ & MWG085 & 3.4 \\
\hline$y m 7$ & H.Hor 3365 & BaMMV & $5 S$ & RWTHAT13 & 0.0 \\
\hline$y m 8$ & $' 10247 ’$ & BaMMV, BaYMV-1 c & $4 \mathrm{~L}$ & MWG2307 & 5.5 \\
\hline$y m 9$ & Bulgarian347 & BaMMV & $4 \mathrm{~L}$ & MWG616, MWG2112 & 0.0 \\
\hline
\end{tabular}

a Only those markers are shown that map closest to the gene; $b$ breeding line used in the experiments to locate the gene, which originally was introgressed from the Chinese accession Mokusekko 3; c mapping data apply to resistance to BaMMV only.

ym8

Genetic mapping was performed in a progeny comprising $108 \mathrm{~F}_{2}$ plants of a cross between the accession '10247' (resistant to BaMMV and BaYMV-1) and cv Trixi (susceptible). Individual progeny plants were tested for resistance to BaMMV. The segregation ratio fitted a 3:1 susceptible/resistant ratio, indicative of the presence of a single, recessive resistance gene. By RFLP mapping the gene was located in the distal portion of the long arm of chromosome 4.

\section{ym9}

Genetic analysis of resistance to BaMMV was carried out in a progeny comprising $64 \mathrm{~F}_{2}$ plants of a cross between Bulgarian 347 (resistant to BaMMV) and cv Alraune (susceptible). Again, the segregation ratio fitted a 3:1 susceptible/resistant ratio. The corresponding recessive gene was also located on the long arm of chromosome 4.

\section{ym5}

To locate this gene, the Japanese cr Iwate Omugi1, which is resistant to BaYMV-1 and BaMMV, was crossed to 2 susceptible cv Copia and Magie. The corresponding progenies consisted of 91 and $80 F_{2}$ plants, respectively. Both segregated for resistance to BaMMV in a 3:1 susceptible/resistant ratio. The corresponding recessive resistance gene was located in the distal portion of the long arm of chromosome 3 . ym5

In order to map a gene conferring resistance to BaYMV-2, $85 \mathrm{DH}$ lines from a cross between the breeding line 'W122/37.1' (resistant to BaYMV-1, BaYMV-2 and BaMMV) and the susceptible $\mathrm{cr}$ Posaune were individually checked against all 3 viruses. Since no recombinant $\mathrm{DH}$ lines could be detected (ie any progeny line was either fully susceptible or fully resistant to all viruses), it is likely that the resistant phenotype is conferred by a single locus, which is located in the telomeric region of the long arm of barley chromosome 3 . The corresponding resistance gene of the breeding line ' $W 122 / 37.1$ ' has been introgressed from the Japanese cv resistant $Y m$ No 1 , which in turn is a progeny line of a cross of the Chinese accession Mokusekko 3 and a susceptible European cv. The fact that $F_{1}$ plants and the entire $F_{2}$ progeny of a cross between Mokusekko 3 and Iwate Omugi 1 were all resistant to BaMMV (Ordon and Friedt, 1993) lends strength to the hypothesis that $y m 5^{\prime}$ represents an allele of the $y m 5$ gene.

\section{DISCUSSION}

\section{Genomic organization of resistance genes}

In the present study 3 novel genes ( $y m 7, y m 8$, $y m 9$ ), which confer resistance to BaMMV, were localized in the barley genome using a set of previously mapped RFLP markers. In addition, closely linked RFLP markers were identified for 
the ym5 gene, conferring resistance to BaMMV and both strains of BaYMV, and a less effective allele $\left(y m 5^{\prime}\right)$, conferring resistance to BaMMV only. Although resistant parents Iwate Omugi1 and accession '10247' condition resistance not only to BaMMV but also to BaYMV-1, the latter could not be investigated in the course of this study since resistance to BaYMV must be tested in field trials which are usually not very reliable on a single plant level. Therefore, further experiments using doubled haploid lines will be carried out to examine, whether resistance to BaMMV and to BaYMV-1 is conditioned by a single gene as is the case for $y m 4$ and $y m 5$. Together with genes previously localized using morphological marker stocks and isoenzymes (Takahashi et al, 1966; Konishi and Kaiser, 1991; lida and Konishi, 1994) or by molecular markers (Graner and Bauer, 1993), 9 resistance genes have been genetically characterized and their approximate chromosomal position is shown in figure 1. Due to the unknown relationship between Japanese and European BaYMV strains, the specificity regarding BaYMV-1 and BaYMV-2 of those resistance genes, which have been studied in Japan, is unknown and is yet to be examined. Among the genes with known specificity against BaYMV1, BaYMV-2 and BaMMV, only one (ym5) is effective against all virus strains. Resistance genes are found on 5 out of the 7 barley chromosomes, but the majority of genes are located on chromosomes 3 and 4 where they map to the distal portion of the long arms, respectively.

The presence of complex loci for disease resistance is not unprecedented for barley, since the Mla locus on chromosome 5, conferring resistance to powdery mildew (Erysiphe graminis), consists of a complex mixture of closely linked genes and multiple alleles (Jahoor et al, 1993). Regarding virus resistance, additional genetic analysis will be required to shed more light on the structure of the presumed complex loci on chromosomes 3 and 4 . In this context, the application of molecular markers will facilitate the identification of progeny plants carrying crossovers close to these gene complexes and will thus dramatically reduce the time and labour required for resistance tests in segregating populations (Bauer et al, 1995).

\section{Breeding for disease resistance}

Considerable portions of the acreage in central Europe are already infested with BaYMV-1 and BaMMV, for example, in the territory of former West Germany the incidence of these 2 viruses is estimated to exceed $60 \%$ (Huth, personal communication). Concerning BaYMV-2, the number of infested fields is rather small yet, but figures are constantly rising and it seems only a matter

\section{Mapped Resistance Genes}
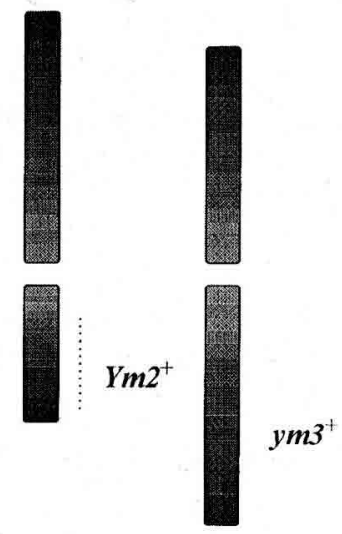

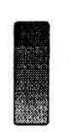

.

$y m 4$
$y m 5$ $y m 5^{\prime \S}$ ymo $\sigma^{+}$
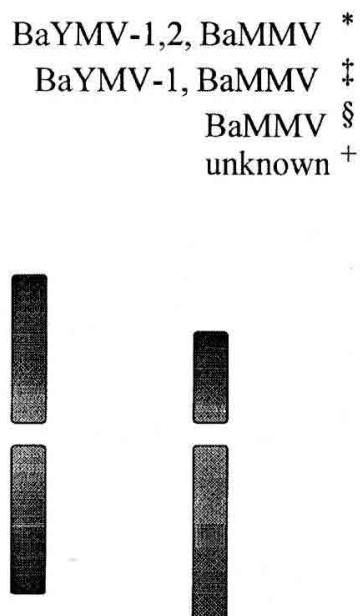

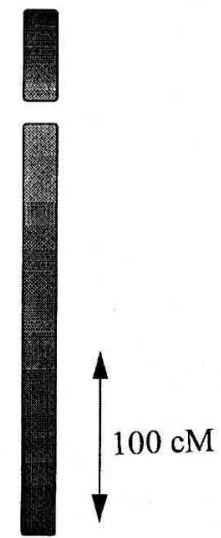

4
5

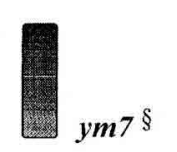

$\mathrm{Ym}^{+}$
$y m 8^{\S}$
$y m 9^{\S}$

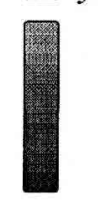

Fig 1. Schematic depiction of the map position of resistance genes conferring resistance to the barley yellow mosaic virus complex. Barley chromosomes are numbered 1 to 7 and have been oriented with their long arm towards the bottom. Chromosomes are drawn based on their genetic length as it has been derived from the Igri x Franka RFLP map (Graner et al, 1991) the total length of which numbers 1500 $\mathrm{cM}$. The approximate position of the $Y m 2$ gene on chromosome 1 is indicated by a dotted line. The specificity of individual genes to the respective members of the barley yellow mosaic complex is marked by appropriate signs as outlined in the legend. 
of time until this virus strain will gain major importance for practical farming. In the long run, the availability of disease-resistant cultivars is of prime importance for a sustained production of winter barley. Until now resistance breeding has relied mainly on conventional tests for disease resistance. However, only BaMMV can be inoculated mechanically at a sufficient infection rate, thus facilitating tests in a growth chamber independently of the growing season. Tests for resistance to BaYMV must be performed in infested fields, which usually contain mixtures of several viruses (eg, BaYMV-1 and BaYMV-2, BaMMV and BaYMV-1, or all 3 viruses), thus frequently impairing a detailed genetic analysis. Moreover, symptom expression varies according to environmental conditions from year to year and early cycle introgressions of novel genes from nonwinter-hardy germplasm are frequently lost by winter killing. However, the availability of molecular markers facilitates selection for the gene itself rather than for the phenotype. The application of appropriate, closely linked RFLP markers, as they are available now for a series of virus resistance genes, dispenses with the need for extensive testing for disease resistance. Moreover, it makes possible the combination of various resistance genes, which, by conventional means, would be a nearly impossible task. In order to further increase the practical value of the technology, a great deal of emphasis is put on the development of PCR-based markers linked to genes for virus resistance (Bauer and Graner, 1995; Ordon et al, 1995). Additional genes effective against BaYMV-2 must also be identified and mapped to further broaden the genetic basis in cultivated barley for resistance.

\section{ACKNOWLEDGMENTS}

The authors are indebted to Dr Foroughi-Wehr and Dr $\mathrm{H}$ Peterka for providing doubled haploid lines. This study was generously supported by Zeneca Seeds, Jealott's Hill, UK and the German Research Foundation (Grants Gr 1317-1-1 and OR 72/1-1).

\section{REFERENCES}

Adams MJ, Swaby AG, Jones P (1988) Confirmation of the transmission of barley yellow mosaic virus (BaYMV) by the fungus Polymyxa graminis. Ann Appl Biol 112, 133-141

Bauer E, Graner A (1995) Basic and applied aspects of genetic analysis of the the $y m 4$ virus resistance locus in barley. agronomie 15, 469-473
Friedt W (1983) Mechanical transmission of soilborne barley yellow mosaic virus. Phytopath $Z$ $106,16-22$

Friedt W (1984) Frühselektion ausf Resistenz gegen Barley Yellow Mosaic Virus durch mechanische Inokutation. Nachrichtenbl Dtsch Pflanzenschutzdienst (Berlin) 36, 179-182

Friedt W, Foroughi-Wehr B (1987) Genetics of resistance to barley yellow mosaic virus. In: Barley Genetics V (S Yasuda, T Konishi, eds), Sanjo Press, Okayama, 659-664

Graner A, Bauer E (1993) RFLP mapping of the ym4 virus resistance gene in barley. Theor Appl Genet 86, 689-693

Graner A, Jahoor A, Schondelmaier J et al (1991) Construction of an RFLP map in barley. Theor Appl Genet 83, 250-256

Heun M, Kennedy AE, Anderson JA, Lapitan N, Sorrells ME, Tanksley SD (1991) Construction of a restriction fragment length polymorphism map for barley (Hordeum vulgare). Genome 34, 437-447

Huth W (1989) Ein weiterer Stamm des barley yellow mosaic virus (BaYMV) gefunden. Nachrichtenbl Dtsch Pflanzenschutzdienst (Berlin) 41, 67

lida $Y$, Konishi T (1994) Linkage analysis of a resistance gene to barley yellow mosaic virus strain II in 2-rowed barley. Breeding Sci 44, 191-194

Jahoor A, Jacob A, Schüller CME, Fischbeck G (1993) Genetical and RFLP studies at the Mla locus conferring powdery mildew resistance in barley. Theor Appl Genet 85, 713-718

Kleinhofs A, Kilian A, Saghai Maroof MA et al (1993) A molecular, isozyme and morphological map of the barley (Hordeum vulgare) genome. Theor Appl Genet 86, 705-712

Konishi T, Kaiser R (1991) Genetic difference in barley yellow mosaic virus resistance between Mokusekko 3 and Misato Golden. Jpn J Breed 41, 499-505

Lander ES, Green P, Abrahamson J et al (1987) MAPMAKER: an interactive computer package for constructing primary genetic linkage maps of experimental and natural populations. Genomics 1, 174181

Ordon F, Götz R, Friedt W (1992) Genetic stocks resistant to barley yellow mosaic viruses (BaMMV, BaYMV, BaYMV-2) in Germany. Barley Genet News/22, 46-50

Ordon F, Friedt W (1993) Mode of inheritance and genetic diversity of BaMMV-resistance of exotic barley germplasms carrying genes different from 'ym4'. Theor Appl Genet 86, 229-233

Ordon F, Bauer E, Friedt W, Graner A (1995) Markerbased selection for the ym4 BaMMV-resistance gene in barley using RAPDs, agronomie 15, 481485

Takahashi R, Hayashi J, Yamamoto H, Moriya I, Hirao (1966) Studies on resistance to yellow mosaic disease in barley. I. A screening test for resistance of 2-rowed and 6-rowed barleys. Nogaku Kenkyu 51, 135-152 